\title{
Donepezil is more effective than galantamine for mild to moderate Alzheimer's disease
}

Jones RW, Soininen $\mathrm{H}$, Hager K, et al. A multinational, randomised, 12-week study comparing the effects of donepezil and galantamine in patients with mild to moderate Alzheimer's disease. Int J Geriatr Psychiatry 2004;19:58-67.

What are the effects of donepezil compared with galantamine in people with mild to moderate Alzheimer's disease?

METHODS

Design Randomised controlled trial.
Allocation Concealed.
assessors blinded).
Sollow up period Twelve weeks.
$\begin{aligned} & \text { Norway. } \\ & \text { Patients } 120 \text { people with mild to moderate Alzheimer's disease } \\ & \text { (minimum age } 50 \text { years; MMSE score } 10-24) \text {, with a caregiver } \\ & \text { willing to participate in the study. Exclusions: previous } \\ & \text { cholinesterase inhibitor treatment; hypersensitivity to } \\ & \text { cholinesterase inhibitors, piperidine, or alkaloids; receiving } \\ & \text { medication that produces anticholinergic effects; other disease. } \\ & \text { Intervention Donepezil (5 mg/day for } 4 \text { weeks increased to } \\ & 10 \text { mg/day for } 8 \text { weeks); galantamine (4 mg twice daily for } \\ & 4 \text { weeks, increased to } 8 \text { mg twice daily for four weeks, then } \\ & 12 \text { mg twice daily for } 4 \text { weeks). } \\ & \text { Outcomes Primary outcome: Physician's and the Caregiver's } \\ & \text { Satisfaction Questionnaires; Secondary outcomes: ADAS-cog; } \\ & \text { MMSE; Disability Assessment for Dementia (DAD) scale. }\end{aligned}$

\section{MAIN RESULTS}

At 12 weeks, physicians and caregivers reported significantly greater overall satisfaction and ease of use for donepezil compared with galantamine (physicians $\mathrm{p}<0.001$; caregivers $\mathrm{p}<0.01$ ). Donepezil significantly improved cognition and activities of daily living compared with galantamine (ADAS-cog: $p<0.05$; MMSE: $p<0.05$; DAD: $\mathrm{p}<0.05)$. More unscheduled clinic visits occurred with galantamine compared with donepezil (5\% donepezil $v 23 \%$

For correspondence: R W Jones, Research Institute for the Care of the Elderly, St Martin's Hospital, Bath, UK; r.w.jones@bath.ac.uk

Sources of funding: Esai Inc, Teaneck, New Jersey and Pfizer Global Pharmaceuticals, Pfizer Inc, New York, USA. galantamine, $\mathrm{p}<0.001)$. Adverse events were more common with galantamine compared with donepezil (67\% donepezil $v 73 \%$ galantamine), particularly gastrointestinal problems (46\% galantamine $v 25 \%$ donepezil).

\section{CONCLUSIONS}

Compared with galantamine, donepezil is easier to use and may improve cognition and functional ability in people with mild to moderate Alzheimer's disease.

\section{Commentary}

Tree cholinesterase inhibitors (donepezil, rivastigmine, and galantamine) are currently available in the UK for treating Alzheimer's disease (the exact number varies in other countries). Although some concerns remain about the analysis of clinical trials in dementia, evidence for the efficacy of cholinesterase inhibitors in treating Alzheimer's based on placebo controlled trials is now quite well established. ${ }^{1}$ Evidence is also emerging for the effectiveness of cholinesterase inhibitors in vascular and Lewy body dementia. Because of differences in trial design and study populations, it has not been possible to conclude whether any of these drugs is more effective or better tolerated than the others- until now with the emergence of head-to-head trials as pharmaceutical companies race to find evidence that sets their drug apart. ${ }^{2}$

The finding that donepezil (a once daily drug with a simple titration regimen) was preferred by clinicians and caregivers to galantamine (twice daily dose, more complex titration) is unsurprising. The secondary outcomes in this study are of greater interest; over a relatively short time span for dementia studies, and with very small numbers, donepezil appeared significantly more effective in improving cognition compared with galantamine. This is even more striking as more people dropped out of the galantamine arm of the trial, which would have exaggerated this drugs performance in Last Observation Carried Forward analyses. This is tantalising evidence that donepezil is the more effective drug.

Some caution is needed here. For example, only the raters were blind to treatment allocation, and the study was sponsored by Eisai and Pfizer which developed and marketed donepezil. Industry sponsored trials with their inherent risk of partisan analysis and reportage may have overemphasised efficacy of other dementia treatments and there remains a compelling need for trials independent of pharmaceutical companies in this area. ${ }^{3}$

James Warner, MD, MRCP, MRCPsych Senior Lecturer in Old Age Psychiatry, Imperial College London, UK

1 Warner J, Butler R, Arya P Dementia. In: Clinical Evidence issue 10. London: BMJ Publishing Group, December 2003.

2 Wilcock $\mathrm{G}$, Howe I, Coles $\mathrm{H}$, et al. A long-term comparison of galantamine and donepezil in the treatment of Alzheimer's disease. Drugs Aging 2003;20:777-89.

3 Koepp R, Miles SH. Meta-analysis of tacrine for Alzheimer's disease: the influence of industry sponsors. JAMA 1999;281:2287-8. 